\title{
Determination of Antioxidant Potential in the Leaf and Flower of Paulownia tomentosa
}

\section{Özge Uğuz (iD)*,, Yeşim Kara (iD)1}

${ }^{1}$ Pamukkale University, Faculty of Arts and Sciences, Department of Biology, Turkey

\begin{abstract}
Paulownia tomentosa, which adapts to the land of Denizli, has a rapid growth feature. In this study, content analysis was carried out in order to determine the antioxidant content of the Paulownia tomentosa tree. According to this, the most much catechin was found in the general phenolic content of the plant $(24035.90 \mu \mathrm{g} / \mathrm{g}$ in the leaf extract, $13837.14 \mu \mathrm{g} / \mathrm{g}$ in the flower extract). The least amount of chlorogenic acid was $(34.863 \mu \mathrm{g} / \mathrm{g}$ in the leaf extract, $82.260 \mu \mathrm{g} / \mathrm{g}$ in the flower extract) found. $\beta$-carotene was obtained as $7716,00 \mu \mathrm{g} / \mathrm{g}$ in leaf content and 501,67 $\mu \mathrm{g} / \mathrm{g}$ in flower contents. Our plant is a plant that contains total phenolic substances in leaf and flower extract. Due to its potential for impact; ethnobotany, is a plant species that can be used in phytotherapy, pharmacology, modern medical applications and animal feed industry.
\end{abstract}

\section{ARTICLE HISTORY}

Received: November 21, 2018

Revised: February 31, 2019

Accepted: March 07, 2019

\section{KEYWORDS}

Paulownia tomentosa, Phenolic Substance, Antioxidant Effect, $\mathrm{DPPH}$,

$\beta$-carotene

\section{INTRODUCTION}

Paulownia tomentosa tree is a species with rapid growth. Paulownia is a species of the family"Scrophulariaceae". The general spread area is China [1]. Paulownia can be planted within the scope of agriculture in many countries such as South Asia, Australia, Japan, Germany and Southern Europe [2]. Today, this tree approximately 2,4 million hectares of agricultural land is cultivated for various purposes [3]. Paulownia in needs high humidity and light. Paulownia prefers undamaged, alluvial soil and unsalted soil types [4,5]. These include: Paulownia tomentosa, Paulownia elongata, Paulownia fortunei, Paulownia catalpifolia, Paulownia kawakamii, Paulownia farbesii, Paulownia albiphloea, Paulownia taiwaniana $[6,7]$. For these species, the most studied and cultured species; Paulownia elongata, Paulownia tomentosa and Paulownia fortunei tree [8,9]. Its stem bark has been used in Chinese herbal medicine as a component of remedies for infectiousdiseases such as gonorrhea and erysipelas [10].

A wide variety of endergonic and exergonic compounds that are mutually interacting to neutralize free radical groups are called antioxidants [11,12]. Antioxidants have the property of slowing the oxidation of fats. Antioxidants are substances that neutralize free radicals in living

${ }^{*}$ CONTACT: Özge Uğuz $\square$ ozge_uguz@hotmail.com $\equiv$ Pamukkale University, Faculty of Arts and Sciences, Department of Biology, 20070, Denizli, Turkey 
things and prevent the cells from being affected or renew themselves [13]. Flavonoids are the polyphenol compound found in each plant and give color to plants. Most flavonoid groups show antioxidant properties in the human body. Neutralizes oxygen-containing, highly reactive molecules, preventing damage to cells $[14,15]$.

There are many substances with antioxidant content. While some of these antioxidants can be produced in our body, others have to be taken from the outside. Research on the source and use of natural antioxidants has shown that some herbs and spices have more antioxidant content than synthetic antioxidants. The body produces these substances for defense purposes. The rapid increase in the side effects of artificial preservatives on health caused an increase in the demand for natural antimicrobial agents. As a result of this increase, researches on herbal substances and their protective effects have accelerated in recent years [16].

Phenolic compounds are substances which contain one or more hydroxyl groups attached to an aromatic ring $[17,18]$. Phenolic compounds have an important effect on the interactions of plants with their environment [19]. Phenolic compounds contain more than 8000 flavonoid groups, most of which are found in leaves, flowers and roots in nature. These groups are thought to exist in the world of plants for many years [20,21]. Vegetable, fruit, nuts, wine, coffee, tea, cocoa and medicinal plants have a high proportion of phenolic compounds [22, 23]. Phenolic acids are natural antioxidant substances found in plants. They provide the unique colors, fragrances and flavors of the plants. These compounds increase the nutritional value and quality of the foods they are present. Phenolic acids; it is used as preservative to extend the shelf life of foods. Besides these properties, plants with phenolic acid content are also used for the treatment of diseases.

$\beta$-carotene exhibits antioxidant properties and prevents the formation of free radicals by preventing the oxidation of unsaturated fats [24]. In addition to its antioxidant effect, one of the best proven tasks of carotenoids is that they have an important provitamin-A activity.

This study; It is aimed to detect antioxidant potential of leaf and flower parts of Paulownia tomentosa. For this purpose, content analysis of antioxidant properties, $\beta$ carotene and phenolic substance contents of the parts of Paulownia tomentosa were performed.

\section{MATERIALS and METHODS}

\subsection{Preparation of Paulownia tomentosa leaf and flower extract}

Paulownia tomentosa leaves and flowers were collected from the campus garden of Pamukkale University in March-April 2017. After drying in the shade, leaves and flowers were pulverized. 1/10 of solvent and ground samples were extracted. 10 grams of milled specimen (leaf and flower) was prepared using 100 milliliters of methanol solvent [25]. It was then extracted with methanol solvent at $55^{\circ} \mathrm{C}$ in a water bath for 5-6 hours. The mixture obtained as a result of the extraction was filtered through filter paper (Whatman No: 1) and the solvents were removed from the rotary evaporator (IKA RV 10 USA). The extract was completely dried in the lyophilizer and the water was removed (Labconco Freezone 6 USA). The remaining extracts were stored at $4{ }^{\circ} \mathrm{C}$ for use in subsequent studies [26].

\subsection{Phenolic compound extraction analysis method}

$2 \mathrm{~g}$ samples were taken from Paulownia tomentosa leaves and flower extracts, $10 \mathrm{ml}$ of \% 96 ethanol was added and 2 minutes were mixed in the homogenizer. It was kept in a water bath at $45^{\circ} \mathrm{C}$ for 1 night and then centrifuged at $4000 \mathrm{rpm}$ for 5 minutes. The insoluble and sediment forming part, was removed by evaporation in the rotary evaporator until it was completely dry at $45^{\circ} \mathrm{C}$. Then the extracts were dissolved in $1 \mathrm{ml}$ methanol and made ready for use in phenolic compound analysis [27]. 0,2 g extract sample was dissolved in mobile phase. Then sample was filtrated in 0,45 $\mu \mathrm{m}$ and was injected to the HPLC. HPLC System: Shimadzu Prominence Brand 
HPLC. CBM: 20ACBM, Detector: DAD (SPD-M20A), Colon Furnace: CTO-10ASVp, Pump: LC20 AT. Autosampler: SIL 20ACHT, Computer Software: LC Solution, Mobile Phase: A: 3\% Formic acid B: Methanol, Column: Zorbax Eclipse XDB-C18 (250* 4,6 mm, 5 micron), Flow Rate: $0,8 \mathrm{~mL} / \mathrm{min}$ [28].

\subsection{Determination of DPPH free radical scavenging activity}

To measure the DPPH radical scavenging activity, Braca et al. Modified method they used. The MeOH DPPH (Sigma) solution was prepared at the concentration $22 \mathrm{~g} \cdot \mathrm{L}-1$. Tested extracts were dissolved in $\mathrm{MeOH}$ at different concentrations. A volume of test solution $(0.2$ $\mathrm{mL}$ ) was mixed with DPPH solution $(1.8 \mathrm{~mL})$ and the absorbance of the mixture at $517 \mathrm{~nm}$ was measured each minute during the first 5 minutes of experiment and than each 5 minutes for the next 25 minutes. Using the recorded data, scavenging effect $r$ was calculated $[r=(1$ - sample absorbance/control absorbance) $\times 100)$ ] and the and the time course of activity increase was drew and the differences between the tested extracts were compared. The percentage of DPPH scavenging was compared to that of the calibrated Trolox standard. Results were expressed in terms of Trolox equivalent antioxidant capacity ( $\mu \mathrm{mol}$ Trolox equivalents per $100 \mathrm{~g}$ dry weight of plant extract) [29].

\subsection{Determination of total antioxidant capacity by $\beta$-carotene}

Carotenoids are highly effective ROS (reactive oxygen species) sweepers. $10 \mathrm{~g}$ of flower and leaf samples were weighed and added to $100 \mathrm{ml}$ of methanol. Methanol was evaporated, the residue was injected into the dissolved phase in the mobile phase.

$\beta$-carotene content was made using Shimadzu Prominence Brand HPLC (Tokyo, Japan) system. CBM: 20ACBM, Detector: DAD (SPD-M20A). Colon Furnace: CTO-10ASVp, Pump: LC20 AT, Autosampler: SIL 20ACHT, Computer Program: LC Solution, Mobile Phase: Methanol / ACN / THF (73/20/7), (v / v / v). Column: ODS 2 (100* 4,6 mm, 5: $\mu \mathrm{m})$, Flow Rate: $1 \mathrm{~mL} / \mathrm{min}$, Injection volume: $20: \mu \mathrm{L}$ [30].

\section{RESULT and DISCUSSION}

\subsection{Phenolic compound analysis findings}

Phenolic substances are important antioxidant components. Substances in every organ of the plants show differences. In the flower extract, gallic acid $(1150,302 \mu \mathrm{g} / \mathrm{g})$, chlorogenic acid $(82,260 \mu \mathrm{g} / \mathrm{g})$, quercetin $(124,579 \mu \mathrm{g} / \mathrm{g})$, luteolin $(144,570 \mu \mathrm{g} / \mathrm{g})$ were higher than leaf extract. In the leaf extract; catechin $(24035,90 \mu \mathrm{g} / \mathrm{g})$, caffeic acid $(1132,779 \mu \mathrm{g} / \mathrm{g})$ and coumaric acid $(140,695 \mu \mathrm{g} / \mathrm{g})$ were obtained more than flower extract. The phenolic substance with the highest effect in the Paulownia tomentosa is the catechin component (Table 1). Standard chromotgram (Figure 1a) and Paulownia tomentosa flowers and leaf chromotgram (Figure 1b) are given graphs. This substance is more present in the leaf extract. Catechin is an important natural antioxidant source [31]. The presence of phenolic substance in Paulownia tomentosa leaf and flower extract indicates that it is a pharmacologically important source. Phenolic substance content analysis of methanolic extract of leaf and flower of Paulownia tomentosa was performed.

Table 1. Phenolic substance analysis results of samples

\begin{tabular}{lccccccc}
\hline $\begin{array}{c}\text { Sample } \\
(\mu \mathrm{g} / \mathrm{g})\end{array}$ & Catechin & Gallic acid & Chlorogenic acid & Caffeic acid & Coumaric acid & Quercetin & Luteolin \\
\hline Flower & 13837,14 & 1150,302 & 82,260 & 879,437 & 88,726 & 124,579 & 144,570 \\
\hline Leaf & 24035,90 & 358,553 & 34,863 & 1132,779 & 140,695 & 58,961 & 102,166 \\
\hline
\end{tabular}




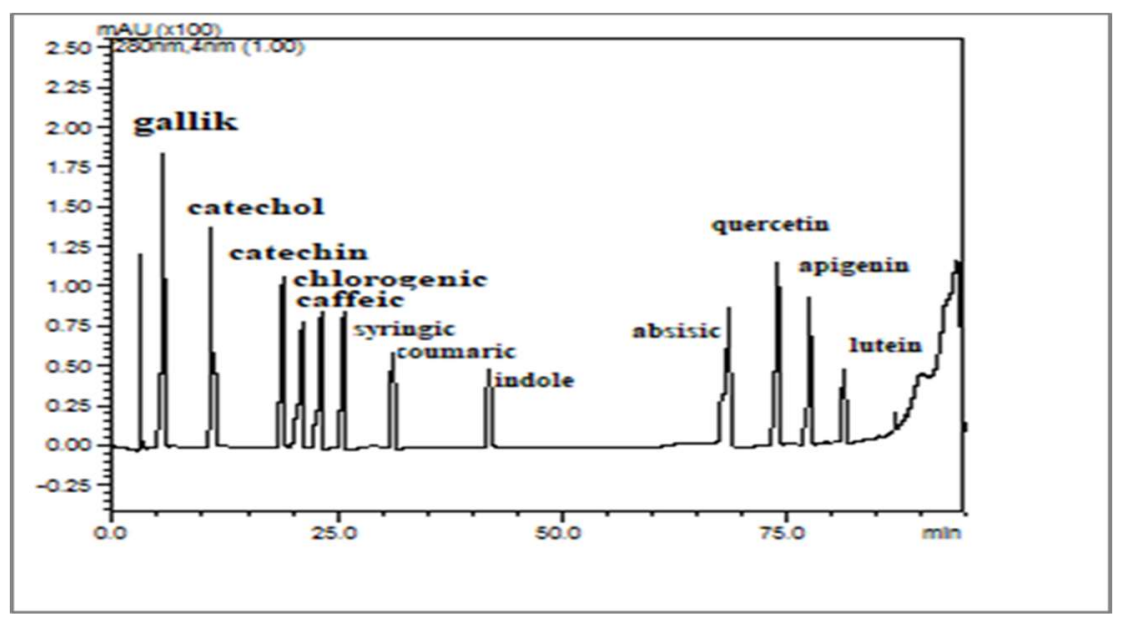

Figure 1a. Chromatogram for phenolic substance standard

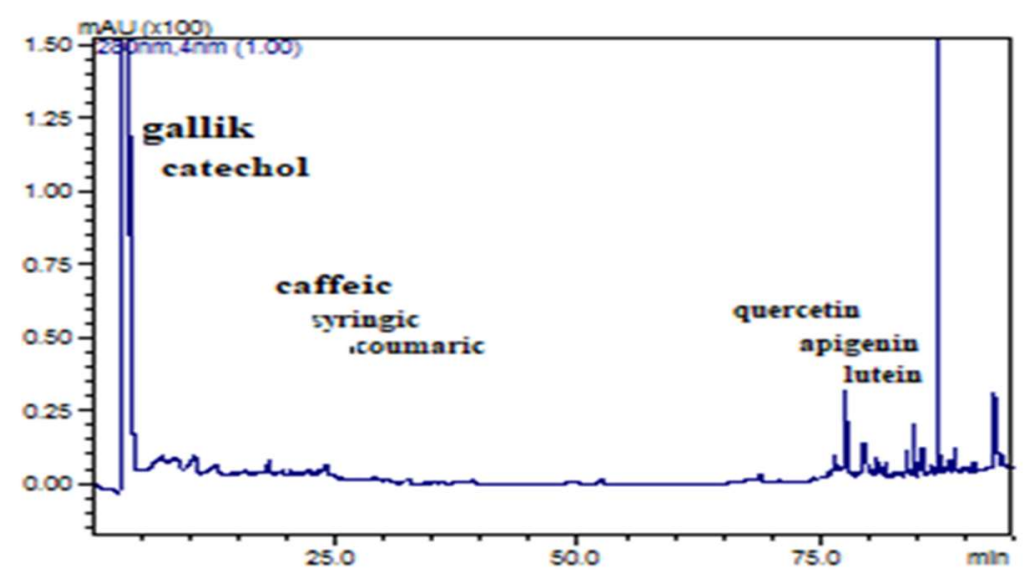

Figure 1b. Chromatogram of Paulownia tomentosa flowers and leaves

Phenolic substances are important antioxidant components. Thanks to these properties, they have an important place in pharmacology. Similar studies have shown that viscous secretion on the surface of Paulownia tomentosa's unripe fruits has a radical inhibitory effect on the flavonones of methanol extract [32].

\subsection{DPPH analysis findings}

While the flower extract was found to be $223,280 \mu \mathrm{molTE} / \mathrm{g}$, the data were obtained as $1104,908 \mu \mathrm{molTE} / \mathrm{g}$ in the leaf extract (Table 2). According to the results of DPPH activity analysis in Paulownia tomentosa's leaf and flower extracts, the amount in the leaf extract is higher than the flower extract.

Table 2. Paulownia tomentosa leaf and flower DPPH analysis results

\begin{tabular}{lc}
\hline Sample & DPPH activity analysis \\
\hline Flower & 223,280 \\
\hline Leaf & 1104,908 \\
\hline
\end{tabular}

A study similar to that of Paulownia tomentosa's fruit extracts was made. In the study, they obtained high antioxidant activity value in fruit extract. They used 3 different solvents in their study and obtained the best result with methanol solvent [33]. In our study, the highest value was obtained from leaf extract. 


\section{3. $\beta$-carotene analysis findings}

According to Table 3, the amount of $\beta$-carotene in the leaf extract $(7716,00 \mu \mathrm{g} / \mathrm{g})$ of Paulownia tomentosa is higher than that of the flower extract $(501,67 \mu \mathrm{g} / \mathrm{g})$. $\beta$-carotene chromotgram standard (Figure 2a) and Paulownia tomentosa leaf and flower samples are given chromotgram graphs (Figure 2b). Carotene substances in the formation of the color of flowers and fruits and photosynthesis helps to have the task as a pigment [34]. The task of carotene on the leaf is to absorb the rays coming from the sun and turn it into chlorophyll. The majority of carotenoid substances in nature show antioxidant activity. According to these results; among the most obvious effects of $\beta$-carotene, which is ultra-violet absorbing feature which is more harmful than normal, has many various medical effects such as antioxidant effect, provitamin A effect, anticancer effect [35].

Table 3. The amount of $\beta$-carotene found in the leaf and flower parts of the Paulownia tomentosa

\begin{tabular}{lc}
\hline Sample $(\mu \mathrm{g} / \mathrm{g})$ & $\beta$-carotene concentration \\
\hline Flower & 501,67 \\
\hline Leaf & 7716,00 \\
\hline
\end{tabular}

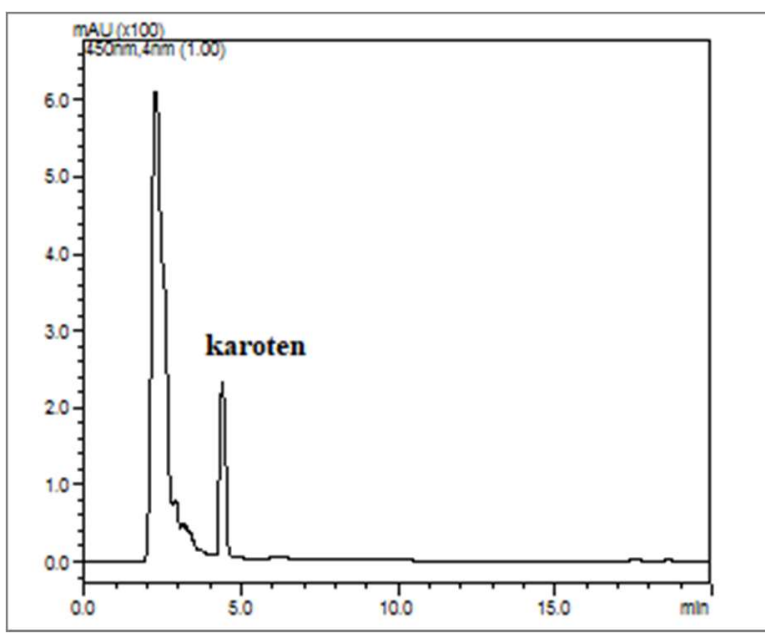

Figure 2a. $\beta$-carotene standard chromatogram

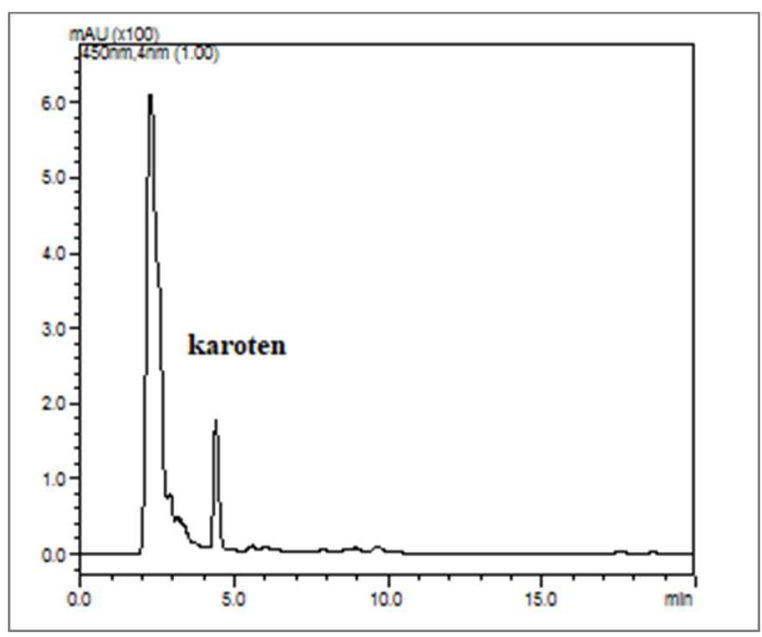

Figure 2b. Leaf and flower sample chromatogram

\section{CONCLUSION}

This study aims to show that Paulownia tomentosa can be used in pharmacology and alternative medicine because of its medical and aromatic potential. The reason for the presence of different amounts of phenolic substances in leaf and flower content; it is thought that the amount of catechin in the leaf is higher as it affects the storage places of the plant's chemical structure. The most common phenolic substance in the Paulownia tomentosa is the catechin component that it has stored in its leaves and flowers. Catechin, a colorless component; Antioxidant has been a natural antioxidant source due to its anti-carcinogenic and obesity prevention effect. Considering these characteristics, it is concluded that both the leaves and flowers of the Paulownia tomentosa are a rich source of antioxidants. Looking at these contents, plant can be used for medical purposes especially in the fight against many diseases, especially cancer. The phenolic substances and antioxidant contents of the leaf and flower extracts of Paulownia tomentosa have the potential to be as effective as synthetic antioxidants. 


\section{Acknowledgements}

This work is Pamukkale University is Supported by the Scientific Research Centre (BAP). Project No: 2017FEBE046.

\section{Conflict of Interests}

Authors declare that there is no conflict of interests.

\section{Orcid}

Özge UĞUZ (iD https://orcid.org/0000-0003-1420-3899

Yeşim KARA (iD https://orcid.org/0000-0002-7027-3667

\section{REFERENCES}

[1] Kaymakc1, A. (2010). Investigations on Some Anatomical, Physical and Mechanical Properties of Paulownia (Paulownia elongata). Master Thesis, Kahramanmaraş Sütçü İmam University, Institute of Science and Technology, Kahramanmaras.

[2] Kaplan, D. (2008). Research on the Possibilities of Using Paulownia Tree in the Pen Industry. Master Thesis, Zonguldak Karaelmas University, Bartın.

[3] Johnson, V.D. (2000). Use of Paulownia for Forest Plantations in the Leon Region of Nicaragua. Chemonics International Inc.

[4] Zhao-Hua, Z., Ching-Ju, C., Xin-Yu, L., Yao Gao, X. (2008). Paulownia in China: Cultivation and Utilization. Asian Network for Biological Science and International Development Research Center, 65. Beijing Chine.

[5] Acar, C., Boza, A., Özkurt, N., Akyüz, M., Şahin Akar, M., Eren, N., Karatay, H. (2008). Some Paulownia Species Adaptation and Promotion of Turkey. Aegean Forestry Research Institute, Publications, 3, 2, İzmir.

[6] Huaxin, Z., (1986). Chinese Paulownia, a Marvellous Tree Species. The Chinese Academy of Forestry, Research Institute of Forestry, Beijing, China.

[7] Ching, C. (1983). Research on the wood properties and utilization of the genus Paulownia. Forestry Science in China, 19, 1-3.

[8] Kays, J., Johnson, D., Stringer, J. (1992). How to Produce and Market Paulownia, Maryland Cooperative Extension. University of Maryland, Bulletin, 319.

[9] Ipekci, Z., Altinkut A., Kazan K., Bajrovic K \& Gozukirmizi N., (2001). High frequency plant rejeneration from nodal explants of Paulownia elongata. Plant Biol., 3, 113-115.

[10] Kang, K.H., Huh, H., Kim, B.K., Lee, C.K. (1999). An antiviral furanoquinone from Paulownia tomentosa Steud. Phytotherapy Res., 13, 624-626.

[11] Seven, A., Candan., G. (1996). Der Antioxidant Defense Systems. Cerrahpaşa Medical Journal, 27 (1), 41-50.

[12] Rice, E. C. (2001). Flavonoid Antioxidants. Curr, Med. Chem., 8, 797-807.

[13] Gök, V., Serteser, A. (2003). Bioavailability of Natural Antioxidants. 3. Food Engineering Congress, Ankara 2-4 October.

[14] Anonim, (2014). Flavon, Flavonoid. Available online: http://www.organikoop.com (Accessed on 20.04.2014).

[15] Mot, C.A., Dumitrescu, S R., Sarbu, C. (2011). Rapid and effective evaluation of the antioxidant capacity of propolis extracts using DPPH bleaching kinetic profiles, FT-IR and UV-VIS spectroscopic data. Journal of Food Composite and Analysis, 24, 516-522.

[16] Bramley, P.M., and Pridham J.B. (1995). The relative antioxidant activites of plant derived polyphenolic flavonoids. Free Radical Research, 22, 375-383.

[17] Dimitrios, B. (2006). Sources of Natural Phenolic Antioxidants. Trends in Food Science \& Technology, 17, 505-512. 
[18] Nichenametla, S.N., Taruscio, T.G., Barney, D.L., Exon, J.H. (2006). A Review of the Effects and Mechanisms of Polyphenolics Cancer. Critical Reviews in Food Science and Nutrition, 46, 161-183.

[19] Harborne, J., (1993). Biochemical Interactions Between Higher Plants. Introduction to ecological biochemistry" Academic Press, London.

[20] Midleton, E., Kandaswami, C., Theoharıdes, T.C. (2000). The Effects of Plant Flavonoids on Mammali Ancells: Implications for Inflammation. Heart Disease, And Cancer. Pharmacological Reviews, 52(4), 673-751.

[21] Ren, W., Q1au, Z., Wang, H., Zhu, L., Zhang, L. (2003). Flavonoids: Promis Inganti Cancer Agents. Medicinal Research Reviews, 23(4), 519-534.

[22] Rice, E.C. (2001). Flavonoid Antioxidants. Curr, Med. Chem., 8,797-807.

[23] Heim, K.E., Tagliaferro, R., Bobılya, D.J. (2002). Flavonoid Antioxidants: Hemistry, Metabolism and Structure-Activity Relationships. The Journal of Nutritional Biochemistry, 13, 572-584.

[24] Paiva, S.A., Russell, R.M., (1999). Beta carotene and other carotenoids asantioxidants. $J$ Am. Coll, Nutr., 18, 426-33.

[25] Faresin, G.E., Tapia, A.A., Bustos, D.A., (2000). Antibakterial activity of some medicinal plants from San Juan, Argentina. Fitoterapia, 71(4), 429-432.

[26] Liu, T.T., Yang, T.S. (2012). Antimicrobial impact of the components of essentiol oil Litsea cubeba from Taiwan and antimicrobial activity of the oil in foof systems. International Journal of Foof Microbiology, 156, 68-75.

[27] Kiselev, K.V., Dubrovina, A.S., Veselova, M.V., Bulgakov, V.P., Fedoreyev, S.A., Zhuravlev, Y.N., (2007). The rol-B gene-induced over production of resveratrol in Vitis amurensis transformed cells. Journal of Biotechnology, 128, 681-692.

[28] Gomes, T., Caponio, F., Alloggio, V. (1999). Phenolic compounds of virgin olive oil: influence of paste preparation techniques. Food Chemistry, 64, 203-209.

[29] Braca, A., de Tommasi, N., di Bari, L., Pizza, C., Politi, M., Morelli, I. (2001). Antioxidant Principles from Bauhinia tarapotensis. J Nat. Prod., 64, 892-895.

[30] Seyhan, U., Bosgelmez, T., G., Canbay, S., H. (2009). Carotene, Phenolic Contents and Antibacterial Properties of Rose Essential Oil, Hydrosol and Absolute. Curr. Microbiol., 59, 554-558.

[31] Agbar, Z.A., Shakya, A.K., Khalaf N., Haroon, M. (2008). Comparative antioksidant activity of some edible plants. Turk J Biol., 32, 193-196.

[32] Asai, T., Hara, N., Kobayashi, S., Kohshima, S., Fujimoto, Y. (2008). Geranylated flavanones from the secretion on the surface of the immature fruits of Paulownia tomentosa. Phytochemistry, 69, 1234-1241.

[33] Karel, S., Holobova, P., Muselik, J., Zima, A. (2007). Antiradical Activity of Paulownia tomentosa (Scrophulariaceae) Extracts. Molecules, 12(6), 1210-1219.

[34] Çöllü, Z., (2007). Urtica Pilulifera L. Investigation of Antioxidant Activity of Plant. M.Sc. Thesis, Ondokuz Mayis University, Institute of Science and Technology, Samsun.

[35] Oliveira, A. H. de., Carneiro, M. S. de S., Sales, R. de O., Pereira, E. S., Araújo Filho, J. M. de., Pinto, M. S. de C., Magalhães, J. A., Costa, N. de L. (2011). Value nutritive of bakery waste in the sheep feeding matter. PUBVET, Londrina, V. 5, N. 8, Ed. 155, Art. 1043. 